Article

\title{
Simulation-based Understanding of the Critical Resolved Shear Stress Relevance for the Fatigue Performance of Metallic Materials
}

\author{
Marijo Mlikota *, Siegfried Schmauder \\ Institute for Materials Testing, Materials Science and Strength of Materials (IMWF), University of Stuttgart, \\ Pfaffenwaldring 32, 70569 Stuttgart, Germany; siegfried.schmauder@imwf.uni-stuttgart.de \\ * Correspondence: marijo.mlikota@uni-stuttgart.de; Tel.: +49-711-685-67674
}

\begin{abstract}
The paper introduces a valuable new description of fatigue strength in relation to material properties and thus a new perspective on the overall understanding of the fatigue process. Namely, a relation between the endurance limits and the accompanying values of the critical resolved shear stress (CRSS) for various metallic materials has been discovered by means of a multiscale approach for fatigue simulation. Based on the uniqueness of the relation, there is a strong indication that it is feasible to relate the endurance limit to the CRSS, and not to the ultimate strength as often done in the past.
\end{abstract}

Keywords: multiscale simulation; fatigue; metals; CRSS; endurance limit

\section{Introduction}

A scientific approach to the question of fatigue strength would be to consider the effects of crystal structure on fatigue mechanisms [1-4]. Researchers from the field of fatigue are aware of the ratio between endurance limit and ultimate tensile strength, $S_{\mathrm{e}} / R_{\mathrm{m}}$ (see Figure 1). This ratio is also known as the fatigue ratio and is typically higher for ferrous materials (including steels - see red line in Figure 1), which are of the body-centered cubic (BCC) type, than for non-ferrous materials (see, e.g., blue line in Figure 1), which possess a face-centered cubic (FCC) crystallographic structure. Furthermore, ferrous materials generally show a pronounced "knee" in the strength-life (S-N, or Wöhler) diagram at about $10^{6}$ cycles, after which the fatigue life curve flattens (see an example in Figure 2). The fatigue strength at this point is known as the endurance limit ( $\left.S_{\mathrm{e}}\right)$. Interestingly, nonferrous materials exhibit a gradual flattening between $10^{7}-10^{8}$ cycles. Although some researchers have explained these effects in terms of strain ageing and dislocation locking (see [4]), there is also evidence that the involved crystal structure plays an important role [1,2].

However, the study from [5] showed that the crystallographic structure is not the predominant factor that determines the shape and position of the fatigue life curves in the $S-N$ diagram, but it is rather the parameter critical resolved shear stress (CRSS). Mlikota and Schmauder [5] reported the existence of a pronounced transition from finite life (slope in the typical $S-N$ curve; see Figure 3) to

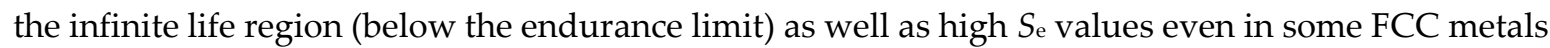
with relatively high CRSS magnitudes. Namely, the higher the CRSS of a certain material, the more pronounced is the transition between the finite and the infinite life region, the higher is the curve position in the diagram and accordingly the higher is its $S_{\mathrm{e}}$ magnitude (see [5] for more details). The present study is the follow-up study of the one published in [5], and brings new insights in the simulation-based understanding of the CRSS for the fatigue performance of metallic materials. 


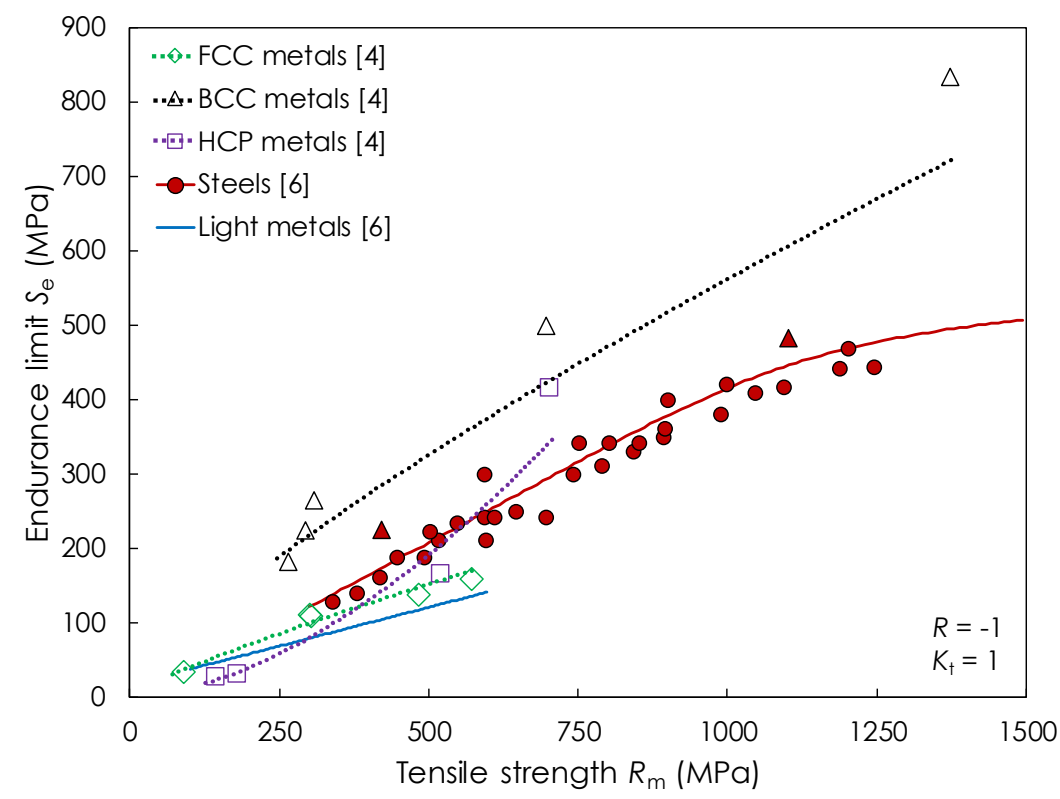

Figure 1. Relation between endurance limit $\left(S_{e}\right)$ and ultimate strength $\left(R_{\mathrm{m}}\right)$ for various metals $[4,6]$.

\section{Materials and Methods}

A study published in [5] by Mlikota and Schmauder dealt with the numerical estimation of the fatigue life represented in the form of $S-N$ curves of metals with BCC and FCC crystallographic structures, and with different magnitudes of the CRSS. An example of simulation-based $S-N$ curve is shown in Figure 2 for BCC steel AISI 1141. Such fatigue life curves are obtained by determining the number of cycles for initiation of a short crack under the influence of microstructure ( $N$ ini; Figure $3 b$ ) and subsequent number of cycles for the growth of the long crack ( $N_{\text {prop; }}$ Figure $\left.3 c\right)$, respectively. Final failure of a specimen or a component occurs at the number of cycles $N_{\mathrm{f}}=N_{\mathrm{ini}}+N_{\text {prop }}$. Micro-models containing microstructures of the materials are set up by using the finite element method (FEM) and are analyzed in combination with the Tanaka-Mura (TM) equation $[7,8]$ in order to estimate the number of cycles required for crack initiation (see Figure $3 \mathrm{~b}$ and especially [5] for more details). The long crack growth analysis is typically based on classical fracture mechanics.

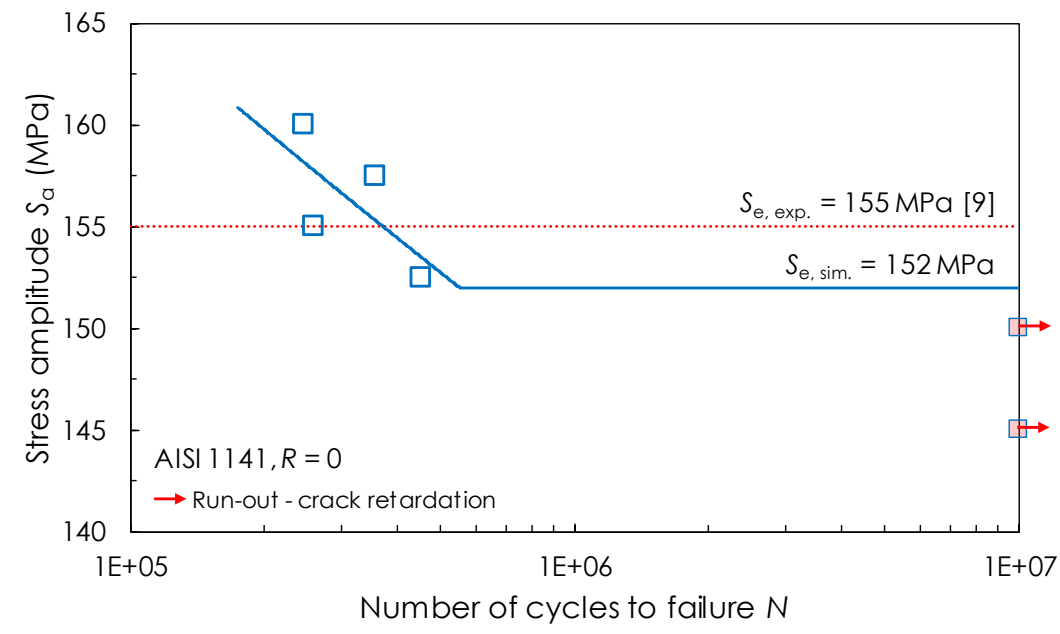

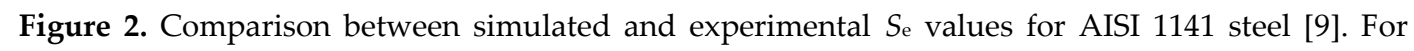
details on the numerical determination of $S_{e}$ values, see $[5,10,11]$. 
A dislocation model forms the physical basis of the TM equation (eq. 1), which is frequently used to determine when a grain, subjected to an outer cyclic loading, will develop a slip band and subsequently a micro-crack. The number of cycles $N_{\mathrm{g}}$ needed for micro-crack nucleation within a single grain can be derived as follows [7,8]:

$$
N_{\mathrm{g}}=8 G W_{\mathrm{c}} /(1-v)(\Delta \tau-2 \mathrm{CRSS})^{2} \pi d,
$$

One of the parameters of the TM model (eq. 1) is the CRSS, which is a threshold value of the shear stress along the glide direction that a dislocation needs to surpass in order to start moving. According to the TM model, micro-cracks form along slip bands (see Figure 3b), depending on grain size (i.e. slip band length) $d$, the average shear stress range $\Delta \tau$ on the slip band, the shear modulus $G$, the crack initiation energy $W_{c}$, Poisson's ratio $v$, and the CRSS [10-14]. A more extended and detailed description of the implementation of the TM equation into FEM-based modelling and simulation of the crack initiation process has been reported in publications of the authors of this study in $[5,10-$ 12,15-18] and by other researchers, too, in [13,14,19,20].

The multiscale approach for fatigue simulation, consisting of the CRSS determination either from micro-pillar tests (MPT) or from molecular dynamics (MD) simulations (both in Figure 3a), crack initiation simulations based on the TM equation (Figure $3 \mathrm{~b}$ ) and long crack growth simulations based on fracture mechanics principles (Figure 3c), has been previously reported in References $[10,15,17,18,21,22]$. The methodology forms the basis of the past [5] and present research work, which has been conducted with the aim to further elucidate the relevance of the parameter CRSS for the fatigue strength in general.

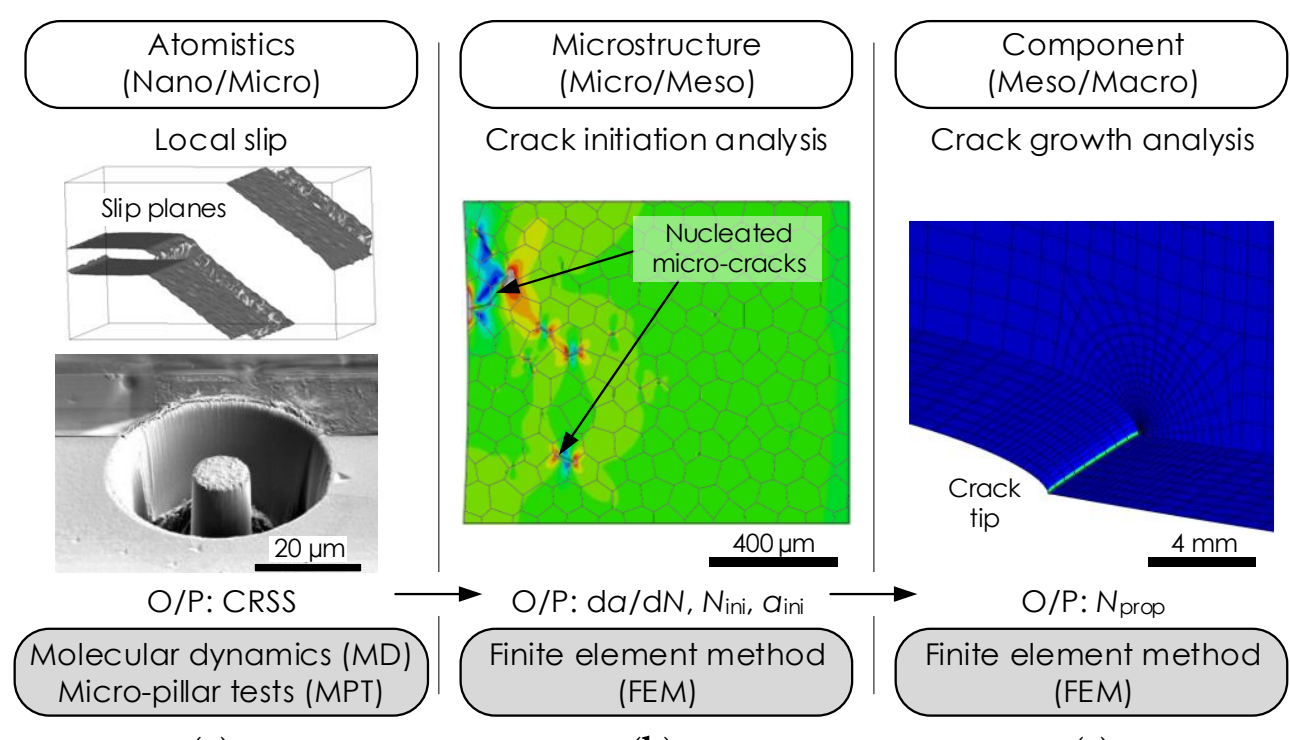

(a)

(b)

(c)

Figure 3. Multiscale approach-Coupling of methodologies at the relevant scales, and accompanying outputs $(\mathrm{O} / \mathrm{P})(\mathrm{CRSS}, \mathrm{d} a / \mathrm{d} N$ - crack growth rate, $N$ ini - number of stress cycles for crack initiation, $N_{\text {prop }}-$ number of stress cycles for crack propagation) $[5,15,16,23]$.

Table 1 contains metallic materials considered in the study from [5] and their mechanical properties; namely the Young's modulus $E$, the shear modulus $G$, the Poisson's ratio $v$, the yield strength $R_{\mathrm{p} 0.2}$ and the ultimate strength $R_{\mathrm{m}}$, their average grain size $d$, and eventually the CRSS values. The details on boundary and loading conditions as well as on specimen geometry that were applied in the study can be found in [5], too. It is suitable to indicate here that all the materials' constitutive laws have been defined as purely elastic, i.e. just by using the elastic material constants. In another study of Mlikota and Schmauder [11] on aluminum alloy AlSi8Cu3, it has been shown that plasticity does influence the fatigue performance of this alloy, however, not significantly.

As reported by several researchers, the CRSS may be up to 100 times as large in BCC steels as in metals with FCC crystal structures. However, after a detailed survey, it has been observed that there exist also certain FCC steels, which have an unusual high CRSS (e.g. austenitic stainless steel AISI 304 
with a 160 MPa high CRSS, see Table 1). As already aforementioned, BCC metals typically show the pronounced transition from finite life to the endurance limit region and, on the other hand, certain FCC metals with a low CRSS show relatively smoother transition between the two regions in the $S$ $N$ diagram. In addition to that, the results from [5] illustrate (see Table 2) the existence of definite endurance limits in the considered BCC (AISI 1141 and Fe 99.9\%) as well as FCC steels (AISI 304 and AA 1050). Despite being an FCC material, the austenitic stainless steel AISI 304 shows an untypically high $S_{e}$ value of $103 \mathrm{MPa}$ (expressed in terms of stress amplitude $S_{\mathrm{a}}$ ), which is higher than the $S_{\text {e value }}$ estimated for the BCC steel AISI 1141 (76 MPa for CRSS = $117 \mathrm{MPa})$. The remaining two investigated metals, the BCC-based pure iron (Fe 99.9\%) and the FCC-based high purity aluminum alloy (AA) 1050 possess, according to the numerical study from [5], relatively low endurance limits, i.e. 22 and $8 \mathrm{MPa}$, respectively.

Table 1. Mechanical properties of the considered metals.

\begin{tabular}{cccccccc}
\hline Material & $\begin{array}{c}\boldsymbol{E} \\
(\mathbf{G P a})\end{array}$ & $\begin{array}{c}\boldsymbol{G} \\
\mathbf{( G P a )}\end{array}$ & $\boldsymbol{v}$ & $\begin{array}{c}\boldsymbol{R}_{\mathbf{p 0 . 2}} \\
\mathbf{M P a})\end{array}$ & $\begin{array}{c}\boldsymbol{R}_{\mathrm{m}} \\
(\mathbf{M P a})\end{array}$ & $\begin{array}{c}\boldsymbol{d} \\
(\boldsymbol{\mu m})\end{array}$ & $\begin{array}{c}\text { CRSS } \\
(\mathbf{M P A})\end{array}$ \\
\hline AISI 304 & 188 & 79.0 & 0.26 & $322[24]$ & $574[24]$ & 30 & $160[28]$ \\
AISI 1141 & 200 & 78.125 & 0.28 & $564[9]$ & $875[9]$ & 60 & $117[15]$ \\
Fe 99.9\% & 205 & 81.0 & 0.28 & $260[25]$ & $414[27]$ & 65 & $35[29]$ \\
AA 1050 & 72 & 26.0 & 0.33 & $95[26]$ & $110[26]$ & 65 & $14[30]$ \\
\hline
\end{tabular}

According to these observations, the magnitude of the CRSS seems to be directly responsible for the magnitude of the simulated $S_{e}$ values of all investigated materials. The simulation-based magnitudes of $S_{\mathrm{e}}$ have been tabulated and compared with the experimental $S_{\mathrm{e}}$ values in Table 2.

Table 2. Simulation-based endurance limits $\left(S_{\mathrm{e}}\right)$ of the investigated materials in comparison with experimental values.

\begin{tabular}{ccccc}
\hline Material & Lattice & CRSS (MPa) & $S_{\text {e }}$ (MPa)/Sim. & $S_{\text {e }}$ (MPa)/Exp. \\
\hline AISI 304 & FCC & $160[28]$ & 103 & $95-111[31,32,33]$ \\
AISI 1141 & BCC & $117[15]$ & 76 & $155[9]$ \\
Fe 99.9\% & BCC & $35[29]$ & 22 & $60-75[34,35]$ \\
AA 1050 & FCC & $14[30]$ & 8 & $10-14[36]$ \\
\hline
\end{tabular}

As visible in Table 2, the numerical study provided relatively good agreement between the calculated $S_{e}$ values with the experimentally determined $S_{e}$ values of some investigated materials (AISI 304 and AA 1050). This observation refers firstly to AISI 304 steel whose numerically determined $S_{e}$ value of $103 \mathrm{MPa}$ is perfectly fitting the span of experimental values (95-111 MPa) that can be found in literature [31-33]. A relatively good agreement, however with a slight underestimation, was achieved for the aluminum alloy AA 1050 (8 versus 10-14 MPa [36]). An exception is the value determined for the steel AISI 1141 of $76 \mathrm{MPa}$, which is considerably lower than the experimental counterpart (155 $\mathrm{MPa}$ [9]). It is expected that a better agreement with the experimental results can be achieved by selecting another - considerably higher - CRSS magnitude. The CRSS of $117 \mathrm{MPa}$ calculated by means of MD for BCC $\alpha$-Fe by Hummel [15] was used in the initial study due to the lack of a more appropriate value for the steel AISI 1141. The reason to expect a higher CRSS magnitude - and by that a higher $S_{e}$ value - for the considered steel AISI 1141 are its improved mechanical properties over iron - achieved by microstructural modifications, i.e. by the addition of small amounts of the micro-alloying elements such as vanadium $(\mathrm{V}, 0.053 \mathrm{wt} \%)$ [9,37]. It is known that such alloying elements contribute to the strength in general, but also to the CRSS magnitude. Another reason to expect a higher CRSS is the relatively high $R_{\mathrm{p} 0.2}$ of around $560 \mathrm{MPa}$ for this steel. Another divergence from the values that can be found in literature is seen for Fe $99.9 \%$; the numerically obtained $S_{\mathrm{e}}$ value of $22 \mathrm{MPa}$ is considerably lower than the experimental values of 60-75 $\mathrm{MPa}$, as reported in [34,35]. Here again the CRSS magnitude could be considered as a reason for the discrepancy. Namely, the CRSS value of $35 \mathrm{MPa}$ extracted from MPT of Rogne and Thaulow [29] is considerably lower than the MD-based $117 \mathrm{MPa}[15]$ for BCC $\alpha$-Fe. 
Interestingly, when these four simulation-based $S_{e}$ values of the investigated metals (see Table 2) are plotted versus their $R_{m}$ values (see Table 1), again a similar observation from Figure 4a follows; Namely, the $S_{\mathrm{e}}-R_{\mathrm{m}}$ points of AA 1050 (purple circle denoted with number 1) and AISI 304 (golden circle denoted with number 4) fall into the range of points characteristic for their groups of materials, i.e. to light metals and steels, respectively. On the other hand, the $S_{\mathrm{e}}-R_{\mathrm{m}}$ points of the two other metals - Fe 99.9\% (green circle denoted with number 2 in Figure 4a) and AISI 1141 (blue circle denoted with number 3 in Figure 4a) - deviate considerably from the points representing steels and BCC metals, in general. This observation suggests, too, that the $S_{e}$ values and by that the CRSS values, too, of the last two metals might be too low.

\section{Results}

When the numerically determined $S_{\mathrm{e}}$ values of the four investigated metals from the initial study published in [5] are plotted with respect to their initially prescribed CRSS values (see both values in Table 2), an interesting relation can be observed, as shown in Figure $4 \mathrm{~b}$. Namely, the $S_{\mathrm{e}}$ and CRSS values relate to each other in a linear manner; despite considering incorrect CRSS values in some cases (Fe 99.9\% and AISI 1141). This newly discovered relation can be expressed by a power-law:

$$
S_{\mathrm{e}}=m_{0} \mathrm{CRSS}^{\mathrm{s}} \text {, }
$$

where $m_{0}$ is the intercept with the y-axis in Figure $4 \mathrm{~b}$ and $s$ the slope of the red dotted line. According to the power-law approximation, $m_{0}$ equals 0.5142 and $s 1.0477$ for loading ratio $R=0$ and stress concentration factor $K_{\mathrm{t}}=2.36$. Interestingly, the slope factor $s$ is approximately equal to 1 in this case. It is noteworthy that the parameters $m_{0}$ and $s$ of equation (2) are dependent on $R$ ratio, $K_{\mathrm{t}}$ etc. A more thorough studies and explanations of these dependencies could be a topic of another follow-up publication.

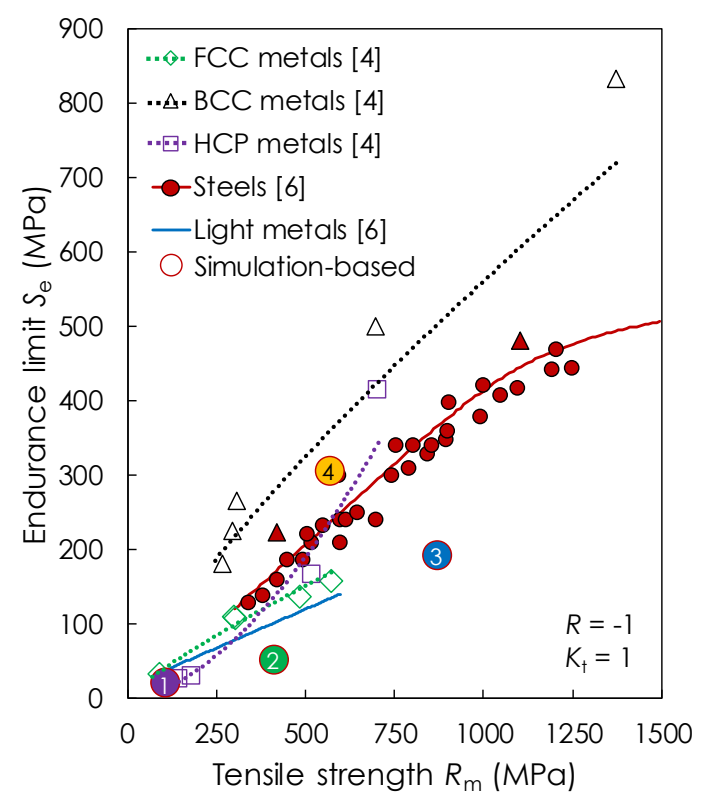

(a)

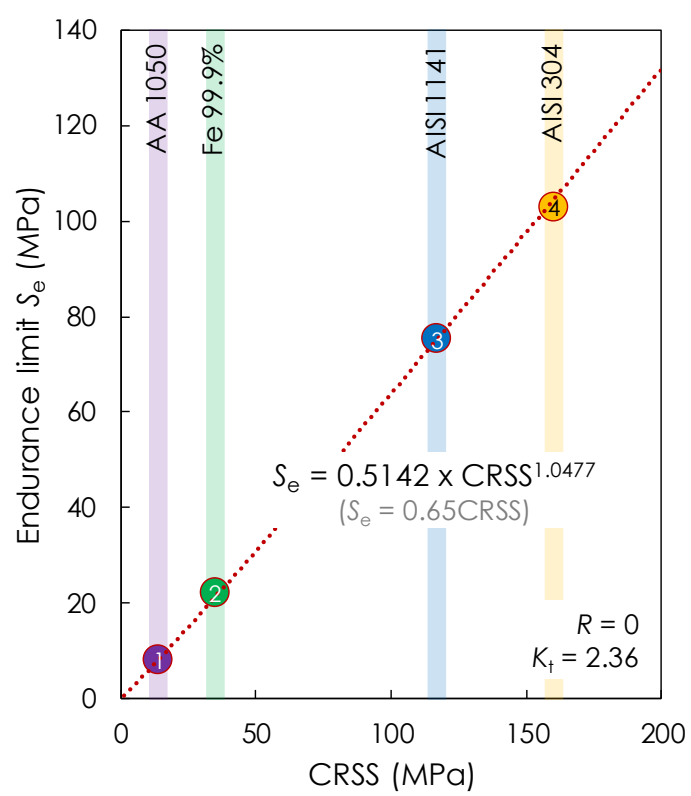

(b)

Figure 4. (a) Relation between endurance limit $\left(S_{e}\right)$ and ultimate strength $\left(R_{\mathrm{m}}\right)$ for various metals $[4,6]$,

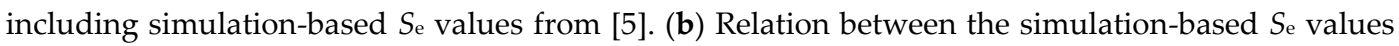
[5] of the investigated metals and their critical resolved shear stress (CRSS) values [15,28-30].

The $S_{\mathrm{e}}$-CRSS relation can be also expressed by using a linear function, as $S_{\mathrm{e}}=0.65 \mathrm{CRSS}$ for these specific $R(=0)$ and $K_{\mathrm{t}}(=2.36)$ values. For other combinations of the $R$ and $K_{\mathrm{t}}$ values, the slope $(0.65$ in this case) would be different (i.e., for $R=-1$ and $K_{t}=1, S_{e}=1.86 C R S S$ ). However, the power-law approximation is preferably used due to higher accuracy, while the simple linear relationship is practically simpler and easier to use. 
Even though based purely on the simulation results and just partly validated, the $\mathrm{Se}_{\mathrm{e}} \mathrm{CRSS}$ relation (eq. 2) can be used as valuable tool in the next step to shed some light on the two cases in Table 2 (Fe 99.9\% and AISI 1141) where the discrepancies with respect to the experimental results have been observed. A rather straightforward case to clarify is the one of Fe $99.9 \%$, where by using the CRSS $=117 \mathrm{MPa}$ [15] for BCC $\alpha$-Fe directly in the Se-CRSS relation, an endurance limit of 75.5 $\mathrm{MPa}$ is obtained, which matches the range of $S_{\mathrm{e}}=60-75 \mathrm{MPa}$ reported in $[34,35]$. To prove the matching also from the numerical side, an additional simulation with the CRSS value of $117 \mathrm{MPa}$ was performed, resulting in an $S_{e}$ value of $74 \mathrm{MPa}$, which lies in the expected $S_{\mathrm{e}}$ range. This could be a confirmation that the initially used and MPT-based CRSS of just $35 \mathrm{MPa}$ [29] is too low. The other case of AISI 1141 can be approached from another side; namely, by knowing the target $S_{e}=155 \mathrm{MPa}$ from the experimental study of Fatemi et al. [9], an estimation of the necessary CRSS to reach this $S_{e}$ value by using the multiscale fatigue simulation approach (see Figure 3) can be done by means of the $S_{\mathrm{e}}$-CRSS relation (eq. 2): CRSS $=\sqrt{ }\left(S_{\mathrm{e}} / m_{0}\right)=1.0477 \sqrt{ }(155 / 0.5142)=232.5 \mathrm{MPa}$. To validate this estimation, is was necessary to perform additional simulations to determine the endurance limit by taking all the input parameters the same as in the study on AISI 1141 from [5] and just by replacing the previously used CRSS of $117 \mathrm{MPa}$ [15] with the new $S_{\mathrm{e}}$-CRSS relation-based value of $232.5 \mathrm{MPa}$. The failure cycles resulting from the $S_{\mathrm{e}}$ simulations are presented in Figure 2 versus the applied amplitude levels $\left(S_{\mathrm{a}}=\right.$ 145-160 MPa, $R=0$ ) and are, at the same place, compared with the experimental result. These results confirm the estimation of the CRSS magnitude of $232.5 \mathrm{MPa}$ for the steel AISI 1141 by using the $\mathrm{Se}_{\mathrm{e}}$ CRSS relation as being correct; the numerically obtained $S_{e}=152 \mathrm{MPa}$ is slightly lower than the experimentally derived $S_{\mathrm{e}}=155 \mathrm{MPa}$ [9], which seems to be an acceptable deviation of $2 \%$ only.

Moreover, Table 2 and Figure 4 can now be revised with the new results for the steel AISI 1141 and for Fe $99.9 \%$ in Table 3 and Figure 5.

Table 3. Simulation-based $S_{e}$ values of the investigated materials (revised with the new results for the steel AISI 1141 and for the Fe 99.9\%, marked with *) in comparison with experimental values.

\begin{tabular}{ccccc}
\hline Material & $\left.\boldsymbol{R}_{\mathrm{m}} \mathbf{( M P a}\right)$ & CRSS (MPa) & $\boldsymbol{S}_{\mathbf{e}}$ (MPa)/Sim. & $S_{\text {e }}$ (MPa)/Exp. \\
\hline AISI 304 & $574[24]$ & $160[28]$ & 103 & $95-111[31,32,33]$ \\
AISI 1141* & $875[9]$ & 232.5 (eq. 2) & 152 & $155[9]$ \\
AISI 1141 & $875[9]$ & $117[15]$ & 76 & $155[9]$ \\
Fe 99.9\%* & $414[27]$ & $117[15]$ & 74 & $60-75[34,35]$ \\
Fe 99.9\% & $414[27]$ & $35[29]$ & 22 & $60-75[34,35]$ \\
AA 1050 & $110[26]$ & $14[30]$ & 8 & $10-14[36]$ \\
\hline
\end{tabular}

It is important to note that no matter correct (i.e. validated by a correct resulting $S_{\mathrm{e}}$ value of an investigated existing material) or incorrect CRSS value, there is always a linear relation (see eq. 2) between the used CRSS value and the numerically obtained $S_{e}$ value, as can be seen in Figures $4 \mathrm{~b}$ and $5 b$.

In addition, and in contrast to the initial data from Figure $4 \mathrm{a}$, the $S_{\mathrm{e}}-R_{\mathrm{m}}$ points of the two revised metals - Fe 99.9\% (green diamond denoted with number 2) and AISI 1141 (blue diamond denoted with number 3) - fall into the acceptable range of points characteristic for steels and BCC metals, as shown in Figure 5a. This suggests that the $S_{e}$ values of these two revised metals should be correct as well as the accompanying CRSS values - similar as those of AA 1050 (purple circle denoted with number 1 in Figure 5a) and AISI 304 (golden circle denoted with number 4 in Figure 5a), which have been considered as being correct already in the initial study from [5].

\section{Discussion}

It follows from these observations that the $\mathrm{e}_{\mathrm{e}}$-CRSS relation (eq. 2) introduces a valuable new description of fatigue strength relations to material properties and a new perspective on the overall understanding of the fatigue process, especially in comparison to contemporary relations where $S_{\mathrm{e}}$ is being related to, e.g., $R_{\mathrm{m}}$ in a non-unique manner (see Figures $4 \mathrm{a}$ and $5 \mathrm{a}$ ). Accordingly, it seems to be more logical to relate $S_{\mathrm{e}}$ to CRSS and not to $R_{\mathrm{m}}$ due to the scattering of $R_{\mathrm{m}}$ that is resulting from 
different strain hardening levels (i.e. cold-working) of the material [38]; in addition to other strengthening mechanisms like grain boundary strengthening and phase boundary strengthening, which on the other hand have no influence on the CRSS (see [5] for more details on the known and applicable linear superpositioning principle of the strengthening mechanisms that contribute to the CRSS magnitude).

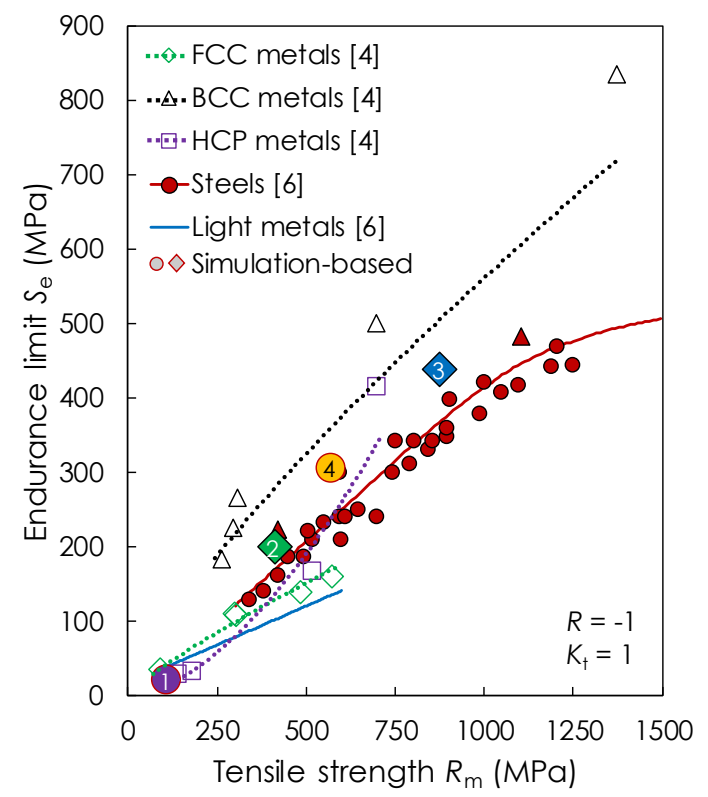

(a)

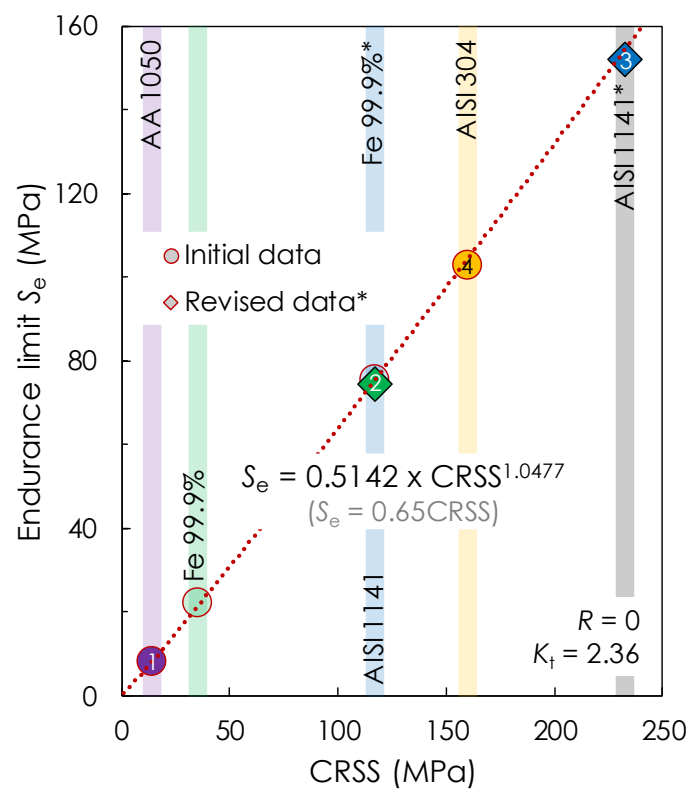

(b)

Figure 5. (a) Relation between $S_{\mathrm{e}}$ and $R_{\mathrm{m}}$ values for various metals [4,6], including simulation-based $S_{e}$ values from Table 3. (b) Relation between $S_{e}$ values (from [5] and updated with the new results for the Fe $99.9 \%$ and for the steel AISI 1141, marked with diamond and with *) of the investigated metals and their CRSS values $[15,28-30]$.

\section{Conclusions}

To conclude, the presented analysis yields a groundbreaking view on the importance of the parameter CRSS for estimating the fatigue strength of metallic materials. The newly discovered linear relation between endurance limit $\left(S_{e}\right)$ and the critical resolved shear stress (CRSS) provides a facet of fatigue theory, which is numerically predictive and which allows the selection of fatigue resistant materials. Furthermore, if proven with additional simulations as well as experimental studies, the $S_{\mathrm{e}}-$ CRSS relation can be used to derive endurance limits of metallic materials solely from their CRSS values - which can be on the other hand estimated from micro-pillar tests, from molecular dynamics simulations or by using the linear superpositioning principle of the strengthening mechanisms that contribute to its magnitude.

Author Contributions: Conceptualization, both authors; methodology, M.M.; validation, M.M.; formal analysis, M.M.; investigation, M.M.; data curation, M.M.; writing-original draft preparation, M.M.; writing-review and editing, both authors; visualization, M.M.; supervision, S.S.; funding acquisition, both authors.

Funding: This research was funded by Deutsche Forschungsgemeinschaft (DFG; German Research Foundation), grant number SCHM 746/222-1.

Acknowledgements: The authors wish to acknowledge gratefully the permission of respected journals and authors to use their data and graphics.

Conflicts of Interest: The authors declare no conflict of interest.

\section{References}

1. Ferro, A.; Montalenti, G. On the effect of the crystalline structure on the form of fatigue curves. Philos. Mag. 1964, 10, 1043. 
2. Ferro, A.; Mazzetti, P.; Montalenti, G. On the effect of the crystalline structure on fatigue: Comparison between body-centred metals (Ta, Nb, Mo and $\mathrm{W}$ ) and face-centred and hexagonal metals. Phil. Mag. J. Theor. Exp. Appl. Phys. 1965, 12, 867-875.

3. Buck, A. Fatigue properties of pure metals. Int. J. Fract. Mech. 1967, 3, 145-152.

4. Grosskreutz, J.C. Fatigue mechanisms in the sub-creep range. ASTM 1971, 495, 5-60.

5. Mlikota, M.; Schmauder, S. On the critical resolved shear stress and its importance in the fatigue performance of steels and other metals with different crystallographic structures. Metals 2018, 8, 883.

6. Dietmann, H. Einführung in die Elastizitäts- und Festigkeitslehre; Alfred Kröner Verlag: Stuttgart, Germany, 1991.

7. Tanaka, K.; Mura, T. A dislocation model for fatigue crack initiation. J. Appl. Mech. 1981, 48, 97-103.

8. Tanaka, K.; Mura, T. A theory of fatigue crack initiation at inclusions. Metall. Trans. A 1982, 13, 117-123.

9. Fatemi, A.; Zeng, Z.; Plaseied, A. Fatigue behavior and life predictions of notched specimens made of QT and forged microalloyed steels. Int. J. Fatigue 2004, 26, 663-672.

10. Mlikota, M.; Schmauder, S.; Božić, Ž. Calculation of the Wöhler (S-N) curve using a two-scale model. Int. J. Fatigue 2018, 114, 289-297.

11. Mlikota, M.; Schmauder, S. Virtual testing of plasticity effects on fatigue crack initiation. In Advances in Engineering Materials, Structures and Systems: Innovations, Mechanics and Applications; Zingoni, A., Ed.; CRC Press, 2019; pp. 587-592.

12. Mlikota, M.; Staib, S.; Schmauder, S.; Božić, Ž. Numerical determination of Paris law constants for carbon steel using a two-scale model. J. Phys. Conf. Ser. 2017, 843, 012042.

13. Glodež, S.; Jezernik, N.; Kramberger, J.; Lassen, T. Numerical modelling of fatigue crack initiation of martensitic steel. Adv. Eng. Software 2010, 41, 823-829.

14. Jezernik, N.; Kramberger, J.; Lassen, T.; Glodež, S. Numerical modelling of fatigue crack initiation and growth of martensitic steels. Fatigue Fract. Eng. Mater. Struct. 2010, 33, 714-723.

15. Božić, Ž.; Schmauder, S.; Mlikota, M.; Hummel, M. Multiscale fatigue crack growth modelling for welded stiffened panels. Fatigue Fract. Eng. Mater. Struct. 2014, 37, 1043-1054.

16. Mlikota, M.; Schmauder, S.; Božić, Ž.; Hummel, M. Modelling of overload effects on fatigue crack initiation in case of carbon steel. Fatigue Fract. Eng. Mater. Struct. 2017, 40, 1182-1190.

17. Mlikota, M.; Schmauder, S. Numerical determination of component Wöhler curve. DVM Bericht 2017, 1684, $111-124$

18. Božić, Ž.; Schmauder, S.; Mlikota, M.; Hummel M. Multiscale fatigue crack growth modeling for welded stiffened panels. In Handbook of Mechanics of Materials; Schmauder, S., Chen, C.-S., Chawla, K.K., Chawla, N., Chen, W., Kagawa, Y., Eds.; Springer Singapore, Singapore, 2018; pp. 1-21.

19. Huang, X.; Brueckner-Foit, A.; Besel, M.; Motoyashiki, Y. Simplified three-dimensional model for fatigue crack initiation. Eng. Fract. Mech. 2007, 74, 2981-2991.

20. Briffod, F.; Shiraiwa, T.; Enoki, M. Fatigue crack initiation simulation in pure iron polycrystalline aggregate. Mater. Trans. 2016, 57, 1741-1746.

21. Božić, Ž.; Mlikota, M.; Schmauder, S. Application of the $\Delta K, \Delta J$ and $\Delta$ CTOD parameters in fatigue crack growth modelling. Tech. Gaz. 2011, 18, 459-466.

22. Božić, Ž.; Schmauder, S.; Mlikota, M. Fatigue growth models for multiple long cracks in plates under cyclic tension based on $\Delta K_{\mathrm{I}}, \Delta J$-integral and $\Delta C T O D$ parameter. Key Eng. Mater. 2011, 488-489, 525-528.

23. Jin, H.-H.; Ko, E.; Kwon, J.; Hwang, S.S.; Shin, C. Evaluation of critical resolved shear strength and deformation mode in proton-irradiated austenitic stainless steel using micro-compression tests. J. Nucl. Mater. 2016, 470, 155-163.

24. Krompholz, K.; Ullrich, G. Investigations into the fatigue crack initiation and propagation behaviour in austenitic stainless steel X5 CrNi 189 (1.4301). Materialwiss. Werkstofftech. 1985, 16, 270-276.

25. Bao, W.P.; Xiong, Z.P.; Ren, X.P.; Wang, F. M. Effect of strain rate on mechanical properties of pure iron. Adv. Mater. Res. 2013, 705, 21-25.

26. Lorenzino, P.; Navarro, A.; Krupp, U. Naked eye observations of microstructurally short fatigue cracks. Int. J. Fatigue 2013, 56, 8-16.

27. Keil, B.; Devletian, J. Comparison of the mechanical properties of steel and ductile iron pipe materials. Pipelines 2011, 1301-1312.

28. Monnet, G.; Pouchon, M. A. Determination of the critical resolved shear stress and the friction stress in austenitic stainless steels by compression of pillars extracted from single grains. Mater. Lett. 2013, 98, 128130. 
29. Rogne, B.R.S.; Thaulow, C. Strengthening mechanisms of iron micropillars. Philos. Mag. 2015, 95, $1814-1828$.

30. Jennings, A.T.; Burek, M.J.; Greer, J.R. Microstructure versus Size: Mechanical properties of electroplated single crystalline Cu nanopillars. Phys. Rev. Lett. 2010, 104, 135503.

31. Boyer, H.E. Atlas of fatigue curves; American Society for Metals: Ohio, USA, 1985.

32. Ben Fredj, N.; Ben Nasr, M.; Ben Rhouma, A.; Sidhom, H.; Braham, C. Fatigue life improvements of the AISI 304 stainless steel ground surfaces by wire brushing. J. Mater. Eng. Perform. 2004, 13, 564-574.

33. Atzori, B.; Meneghetti, G.; Ricotta, M. Analysis of the fatigue strength under two load levels of a stainless steel based on energy dissipation. Frattura Integr. Strutt. 2011, 17, 15-22.

34. Lipski, A. Determination of the S-N curve and the fatigue limit by means of the thermographic method for ductile cast iron. AIP Conf. Proc. 2018, 2028, 020008.

35. Islam, M.A.; Sato, N.; Tomota, Y. Tensile and plane bending fatigue properties of pure iron and ironphosphorus alloys at room temperature in the air. Trans. Indian Inst. Met. 2011, 64, 315-320.

36. Sakin, R. Investigation of bending fatigue-life of aluminum sheets based on rolling direction. Alex. Eng. J. 2018, 57, 35-47.

37. Yang, L.; Fatemi, A. Impact resistance and fracture toughness of vanadium-based microalloyed forging steel in the as-forged and Q\&T conditions. J. Eng. Mater. Technol. 1996, 118, 71-79.

38. Schijve, J. Fatigue of Structures and Materials; Springer Netherlands, Netherlands, 2009. 